\title{
Improved Efficiency of Flexible Organic Light-Emitting Diodes by Insertion of Ultrathin $\mathrm{SiO}_{2}$ Buffer Layers
}

\author{
Chien-Jung Huang, ${ }^{1}$ Kan-Lin Chen, ${ }^{2}$ Po-Wen Sze, ${ }^{3}$ Wen-Ray Chen, \\ Teen-Hang Meen, ${ }^{4}$ and Shi-Lun $\mathrm{Wu}^{5}$ \\ ${ }^{1}$ Department of Applied Physics, National University of Kaohsiung, Kaohsiung 81148, Taiwan \\ ${ }^{2}$ Department of Electronic Engineering, Fortune Institute of Technology, Kaohsiung 83160, Taiwan \\ ${ }^{3}$ Department of Electro-Optical Science and Engineering, Kao Yuan University, Kaohsiung 82151, Taiwan \\ ${ }^{4}$ Department of Electronic Engineering, National Formosa University, Hu-Wei, Yunlin 63201, Taiwan \\ ${ }^{5}$ Department of Electrical Engineering, Southern Taiwan University of Technology, Tainan 71005, Taiwan
}

Correspondence should be addressed to Chien-Jung Huang; chien@nuk.edu.tw and Kan-Lin Chen; klchen@fotech.edu.tw

Received 15 September 2013; Accepted 3 October 2013

Academic Editor: Liang-Wen Ji

Copyright (c) 2013 Chien-Jung Huang et al. This is an open access article distributed under the Creative Commons Attribution License, which permits unrestricted use, distribution, and reproduction in any medium, provided the original work is properly cited.

An ultrathin hole-injection buffer layer (HBL) using silicon dioxide $\left(\mathrm{SiO}_{2}\right)$ by electron beam evaporation in flexible organic lightemitting diode (FOLED) has been fabricated. While the current of the device at constant driving voltage decreases as increasing $\mathrm{SiO}_{2}$ thickness. Compared to the different thicknesses of the buffer layer, the FOLED with the buffer layer of $4 \mathrm{~nm}$ showed the highest luminous efficiency. The atomic force microscopy (AFM) investigation of indium tin oxide (ITO)/ $\mathrm{SiO}_{2}$ topography reveals changes at the interface between $\mathrm{SiO}_{2}$ and $\mathrm{N}, \mathrm{N}^{\prime}$-bis-(1-naphthl)-diphenyl-1,1'-bipheny-4,4'-diamine (NPB), resulting in ultrathin $\mathrm{SiO}_{2}$ layers being a clear advantage for a FOLED. However, the $\mathrm{SiO}_{2}$ can be expected to be a good buffer layer material and thus enhance the emission performance of the FOLED.

\section{Introduction}

In the recent years, organic light-emitting diodes (OLED) have gained great interest in the last decade due to their potential application in efficient, large-area, and full-color displays [1-4], especially for flexible displays application [58]. The quantum efficiency, photons emitted per electron injected, is dependent upon the current balance between electrons and holes and therefore upon the charge injection rates at cathode and anode interfaces. Current balance is especially difficult to achieve in devices with only a single organic layer since there are no energy barriers to block carrier transit from electrode to electrode. It, therefore, becomes critical to achieve the best possible current balance by suitable choice of materials $[9,10]$. The injection currents depend primarily on Schottky barrier heights at each electrode. Furthermore, corroborating evidence for the important injection rate using physical hole-injection buffer layer (HBL) deposited on the anode. Recently, few studies have reported that an ultrathin film of oxide is employed as an anode buffer layer in organic light-emitting devices to enhance the hole transport and power efficiency of OLED [11-13]. In other words, the buffer layer enhances most of the holes injected from the anode and improves the balance of the hole and electron injections. Although these studies can improve their efficiency, to accurately control the evaporation rate and the concentration of two or more materials, such as molybdenum oxide $\left(\mathrm{MoO}_{3}\right)$, zinc oxide $(\mathrm{ZnO})$, and silicon dioxide $\left(\mathrm{SiO}_{2}\right)$, in the doping codeposition process is very difficult.

Among these materials, the cost of $\mathrm{SiO}_{2}$ material is cheaper than that of the other two materials. However, if a thin insulating layer such as silicon dioxide $\left(\mathrm{SiO}_{2}\right)$ with a wide bandgap ( $8 \mathrm{eV}$, compared to $2.9 \mathrm{eV}$ for 8 -hydroxyquinoline aluminum $\left(\mathrm{Alq}_{3}\right)$ ) is added between the indium tin oxide (ITO) anode and N, $\mathrm{N}^{\prime}$-bis-(1-naphthl)-diphenyl-1,1'bipheny-4,4'-diamine (NPB) layer, the accumulation of holes can occur at the ITO/NPB interface; hence, the improvement 


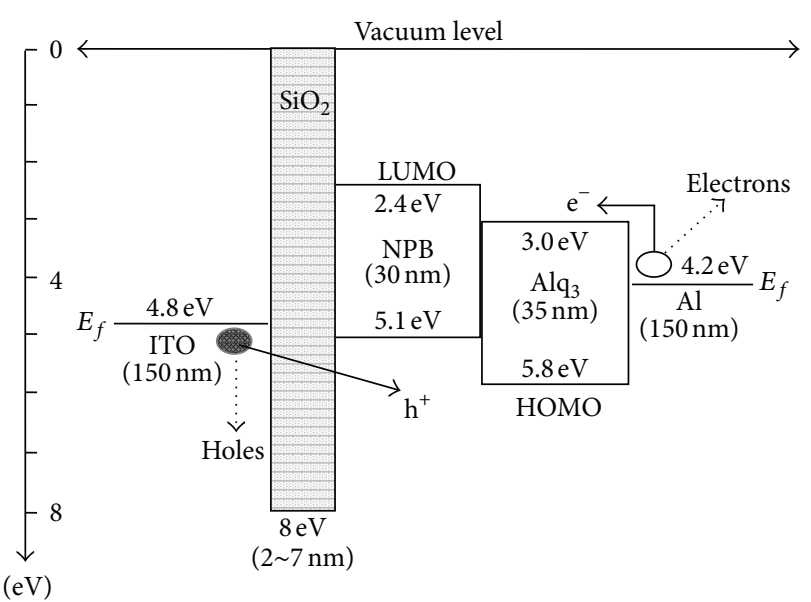

Figure 1: The schematic energy level diagram of $\mathrm{ITO} / \mathrm{SiO}_{2} / \mathrm{NPB} /$ $\mathrm{Alq}_{3} / \mathrm{Al}$.

is of current balance between the injected electrons and holes. The inserted buffer layer has not yet been studied. In this paper, a detailed investigation of an ultrathin $\mathrm{SiO}_{2}$ layer as the $\mathrm{HBL}$ and the effect of $\mathrm{SiO}_{2}$ on the device efficiency is presented.

\section{Experimental}

For the fabrication of flexible organic light-emitting diode (FOLED), the devices were performed on $150 \mathrm{~nm}$ thickness of indium tin oxide (ITO)-coated plastic substrate. The schematic energy level diagram of the FOLED with the $\mathrm{SiO}_{2}$ layer inserted between ITO/NPB interface structures is shown in Figure 1. The sheet resistance of ITO was obtained at $50 \Omega /$ sq. The plastic substrate used in this study is a transparent polymer named ARTON (ARTON F, JSR Co., Ltd., Japan). The ITO film is streaked with the photolithography processing via etching and is as an anode electrode. The device configuration was adopted as shown in Figure 2. The multilayer structure consists of an ITO-coated plastic substrate, ultrathin $\mathrm{SiO}_{2}$ as an $\mathrm{HBL}, \mathrm{NPB}$ as a hole-transporting layer (HTL), $\mathrm{Alq}_{3}$ as an electron-transporting layer (ETL), and aluminum (Al) cathode electrode manufactured by shadow mask. The thickness of ITO, NPB, $\mathrm{Alq}_{3}$, and $\mathrm{Al}$ was performed at $150,30,35$, and $150 \mathrm{~nm}$, respectively. The emitting area of devices is $2.25 \mathrm{~mm}^{2}$. After the previously mentioned multilayer structure, the $\mathrm{SiO}_{2}$ layer is fabricated by using the electron beam deposition (EBD) system. The evaporation onto the ITO-covered plastic substrate is performed in a high vacuum system with a base pressure of $1.0 \times 10^{-6}$ torr. The $\mathrm{Al}$ was deposited by EBD system at rates of $1 \mathrm{~nm} / \mathrm{sec}$. The brightness is measured by spectrophotometer (Photo Research, PR655 SpectraScan, USA). The characterization was carried out by using the power source (Keithley Source Meter 2400, USA). The present study also presents a complementary study of the topography of the surfaces by atomic force microscopy (AFM, Burleigh, METRIS-3345, USA).

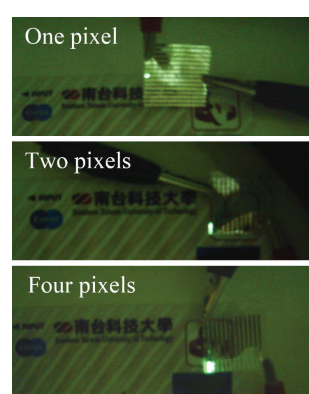

(a)

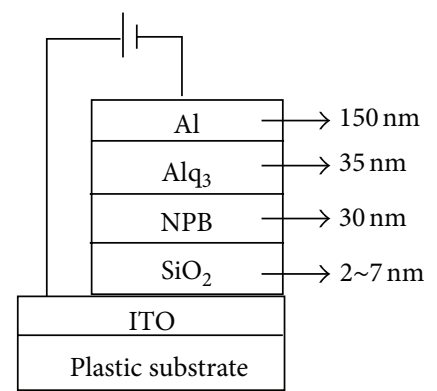

(b)
Figure 2: Photographs (a) of flexible organic light-emitting diode at an applied voltage of $6 \mathrm{~V}$ and schematic diagram of device configuration (b).

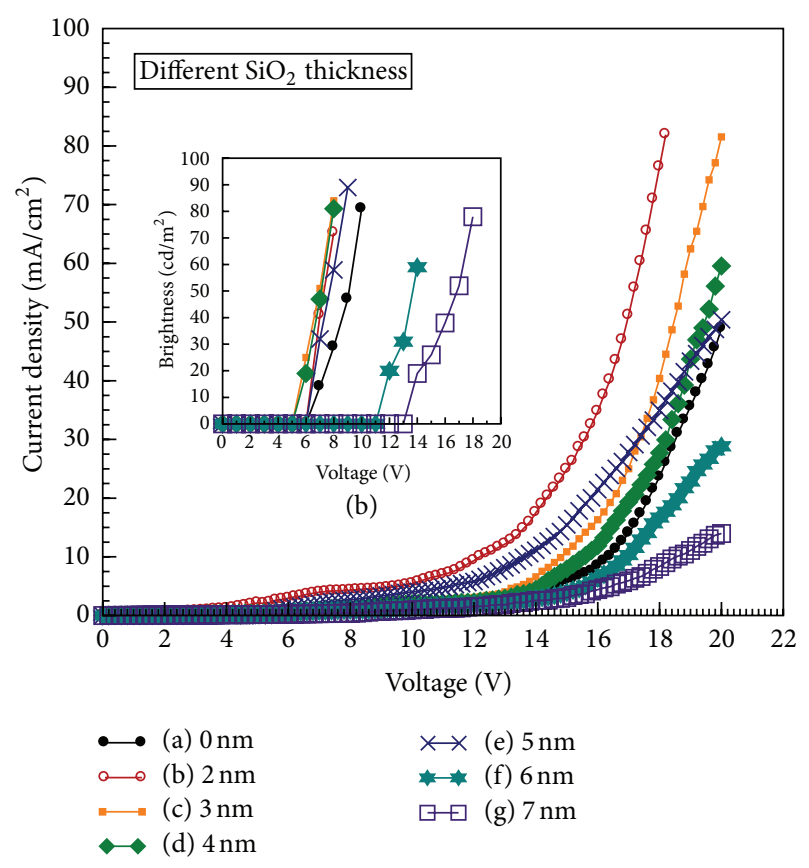

(a)

FIGURE 3: (a) $J-V$ characteristics of the devices with different silicon dioxide thicknesses. (b) The inset shows the $B-V$ characteristics of the devices.

\section{Results and Discussion}

Figure 3(a) shows typical current density versus applied voltage $(J-V)$ characteristics of the studied devices fabricated with different thicknesses of $\mathrm{SiO}_{2}(0,2,3,4,5,6$, and $7 \mathrm{~nm})$. The current density of the devices is almost zero under negative voltage. As expected, the current density decreases as the buffer layer thickness increases when the buffer layer of $\mathrm{SiO}_{2}$ is larger than $5 \mathrm{~nm}$ at a constant applied voltage of $14 \mathrm{~V}$. On the other hand, there is a tendency that current density increases with the decrease of the thickness of the buffer layer $(2 \sim 4 \mathrm{~nm})$. This suggests that the buffer layer is as a block layer and has an effect of blocking the hole in movement, leading to more balance. In other words, this barrier impedes hole 
injection from ITO, preventing the accumulation of excess holes in the luminance layer, thus increasing the probability of $\mathrm{e}-\mathrm{h}^{+}$pair combination.

It is known that holes are the major charge carrier in FOLED, and luminous efficiency strongly depends on charge balance. Luminous intensity therefore increases with the increase of barrier height and with the thickness of the buffer layer $(2 \sim 4 \mathrm{~nm})$ when the applied voltage is less than $8 \mathrm{~V}$. It shows that the bias voltage to obtain the same current density of $20 \mathrm{~mA} / \mathrm{cm}^{2}$ is obviously lowered for the FOLED with $2 \mathrm{~nm}$ $\mathrm{SiO}_{2}$ buffer layer compared with the devices without $\mathrm{SiO}_{2}$. Furthermore, the light onset voltage $\left(V_{L \text {-on }}\right.$; defined as the voltage required to drive a luminance of $10 \mathrm{~cd} / \mathrm{m}^{2}$ ) of the device with $\mathrm{SiO}_{2}$ of $4 \mathrm{~nm}$ is as low as $5.2 \mathrm{~V}$, as shown in the inset of Figure 3(b). In other words, the $V_{L \text {-on }}$ in Figure 3(b) is estimated to be 7.1, 6.2, 5.1, 5.2, and $6.5 \mathrm{~V}$ for devices with buffer layer in $0 \mathrm{~nm}, 2 \mathrm{~nm}, 3 \mathrm{~nm}, 4 \mathrm{~nm}$, and $5 \mathrm{~nm}$, respectively. Thus, the $V_{L-\text { on }}$ of $2 \mathrm{~nm}, 3 \mathrm{~nm}, 4 \mathrm{~nm}$, and $5 \mathrm{~nm}$ is to be lower than that of the device without buffer layer. However, there is a tendency that the $V_{L \text {-on }}$ increases with the increase of oxide thickness $(2 \sim 7 \mathrm{~nm})$ because a larger voltage is dropped across the oxide [14]. When the oxide layer is more than $5 \mathrm{~nm}$, the effective barrier is as (1) [15]

$$
\begin{gathered}
\Phi_{B}^{\prime}=\Phi_{B}-\left(q \frac{\left|E_{S}\right|}{4 \pi \varepsilon \varepsilon_{o}}\right)^{1 / 2}-\alpha\left|E_{S}\right|, \\
D_{m}=\left[\frac{q}{16 \pi \varepsilon_{o} E}\right]^{1 / 2}, \\
\Delta \Phi=\left[\frac{q E}{4 \pi \varepsilon_{o}}\right]^{1 / 2},
\end{gathered}
$$

where $E_{S}$ is the NPB surface field and $\Phi_{B}$ is the potential barrier height when $E_{S}=0$. The image force exerted by ITO proximity and the thermally assisted tunneling through the barrier lowers the effective barrier height. Equations (2) and (3) show the relationship between $\Delta \Phi$ and $D_{m}$, where $D_{m}$ is the distance from the ITO. From the previous equation and viewpoints, there is an image force at smaller $D_{m}$ which results from increasing oxide thickness and lowers considerably the barrier. In other words, the barrier height is inversely proportional to oxide thickness. With lowered barrier, there follows an excess of hole injection and accumulation. However, improved hole/electron injection balance is a consequence one may expect from the inclusion of $\mathrm{SiO}_{2}$ ultrathin film as HBL. Besides, the electrons possess much lower mobility than holes in organic materials. This gives rise to an accumulation of excess holes at $\mathrm{SiO}_{2}-\mathrm{NPB}$ boundary. The electron-hole pair combination is decreased, so the luminous efficiency is decreased.

Figure 4(a) shows the brightness versus applied voltage $(B-V)$ characteristics of the FOLED with the $\mathrm{SiO}_{2}$ buffer layer. In contrast with the value of only $2300 \mathrm{~cd} / \mathrm{m}^{2}$ without $\mathrm{SiO}_{2}$ buffer layer, an impressive brightness of more than $3300 \mathrm{~cd} / \mathrm{m}^{2}$ was measured when the $\mathrm{SiO}_{2}$ thickness was $2 \mathrm{~nm}$ at $20 \mathrm{~V}$. Similarly, the luminous efficiency of the FOLED was increased due to the introduction of the thin $\mathrm{SiO}_{2}$ layer (Figure 5). Figure 4(b) shows the brightness versus current

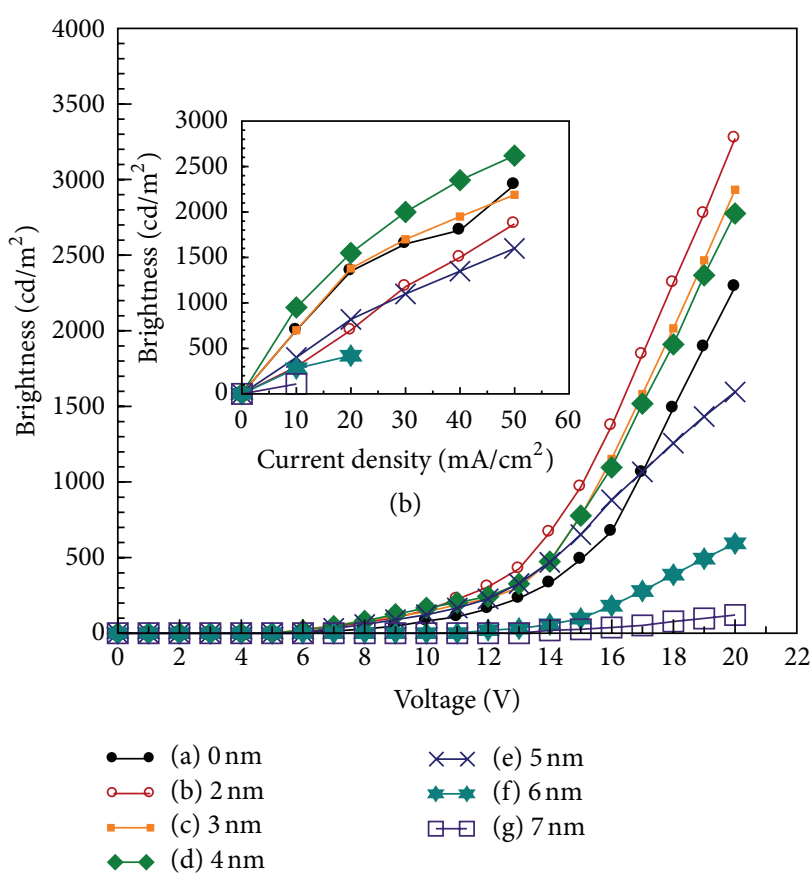

(a)

Figure 4: (a) $B-V$ characteristics for the devices with different $\mathrm{SiO}_{2}$ buffer layer thicknesses. (b) The inset shows the $B-J$ characteristics of the devices.

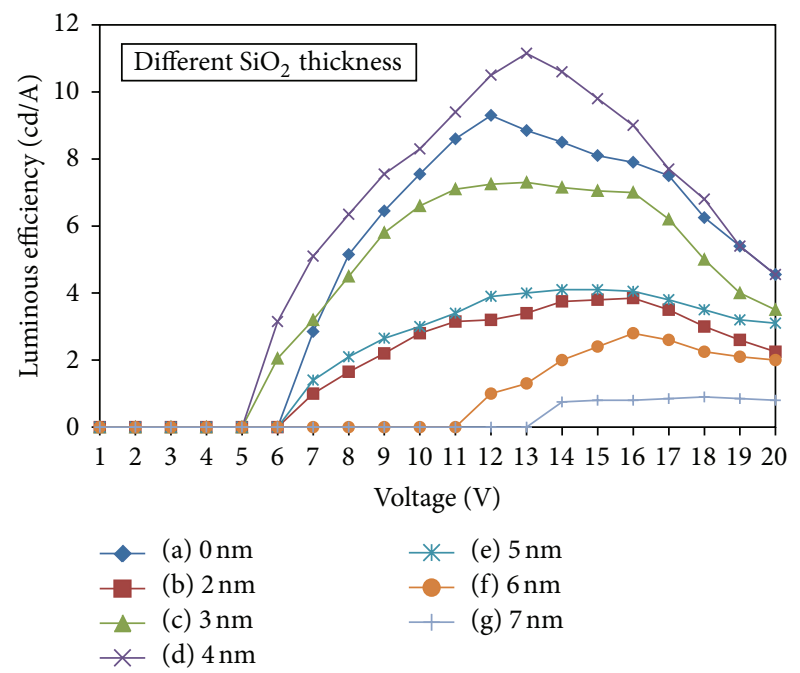

FIGURE 5: Luminous efficiency versus applied voltage curves of the devices with different buffer layer thicknesses.

density $(B-J)$ on the $\mathrm{SiO}_{2}$ thickness for the devices. At a given constant current density of $20 \mathrm{~mA} / \mathrm{cm}^{2}$, the device with buffer layer of $4 \mathrm{~nm}$ displayed the highest luminance of $1550 \mathrm{~cd} / \mathrm{m}^{2}$ among the seven samples which corresponded to a luminous efficiency of $7.6 \mathrm{~cd} / \mathrm{A}$. In contrast, the device without the $\mathrm{SiO}_{2}$ buffer layer only shows the luminous efficiency of $6.4 \mathrm{~cd} / \mathrm{A}$ at the current density of $20 \mathrm{~mA} / \mathrm{cm}^{2}$. Table 1 showed the luminance and efficiency characteristics for the devices with different thicknesses of $\mathrm{SiO}_{2}$ at the 


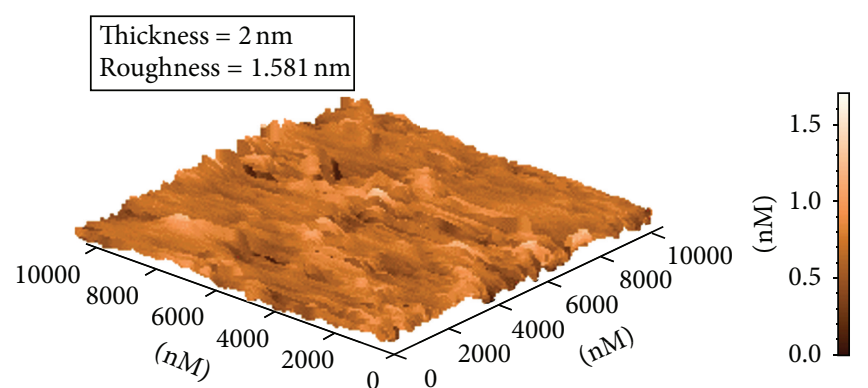

(a)

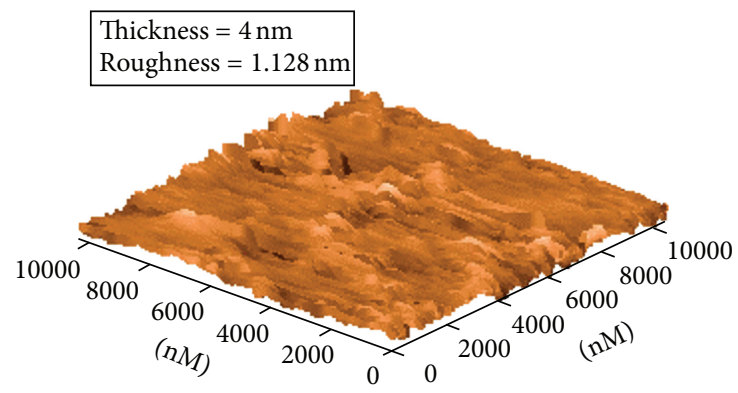

(c)

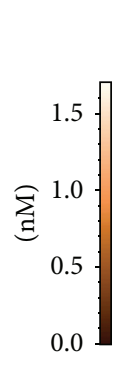

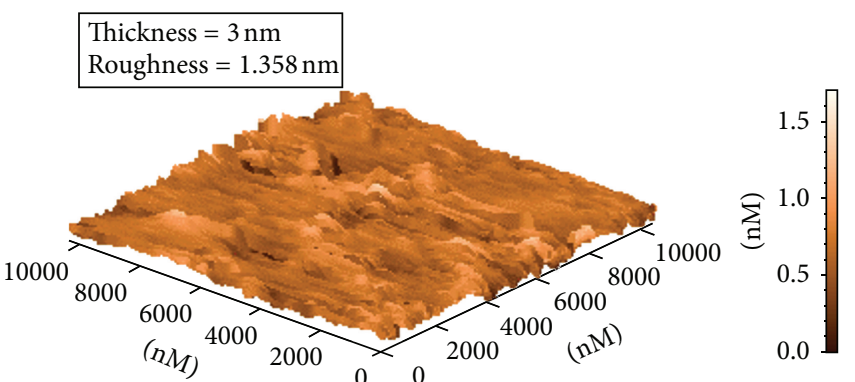

(b)
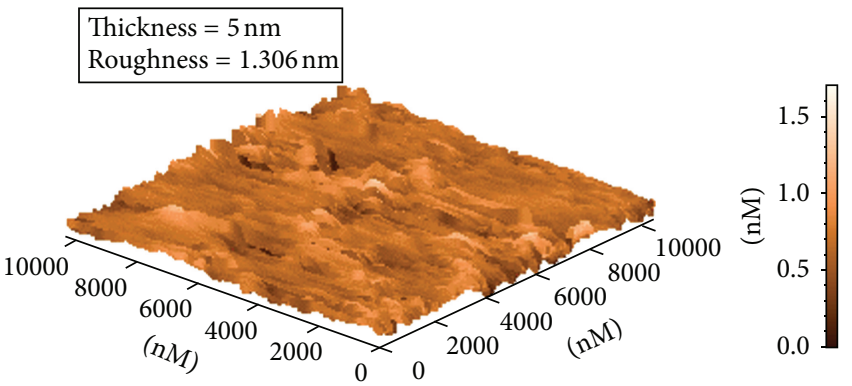

(d)

Figure 6: Images of atomic force microscopy of the ITO surface after depositing (a) 2, (b) 3, (c) 4, and (d) 5 nm $\mathrm{SiO}_{2}$ buffer layers.

TABLE 1: Luminance and efficiency characteristics for the devices with different $\mathrm{SiO}_{2}$ buffer layer thicknesses at the current density of $20 \mathrm{~mA} / \mathrm{cm}^{2}$.

\begin{tabular}{lccc}
\hline $\begin{array}{l}\mathrm{SiO}_{2} \text { thickness } \\
(\mathrm{nm})\end{array}$ & $\begin{array}{c}\text { Luminance } \\
\left(\mathrm{cd} / \mathrm{m}^{2}\right)\end{array}$ & $\begin{array}{c}\text { Voltage } \\
(\mathrm{V})\end{array}$ & $\begin{array}{c}\text { Luminous } \\
\text { efficiency }(\mathrm{cd} / \mathrm{A})\end{array}$ \\
\hline 0 & 1310 & 17.8 & 6.4 \\
2 & 700 & 14.2 & 3.8 \\
3 & 1380 & 16.8 & 6.5 \\
4 & 1550 & 17.1 & 7.6 \\
5 & 820 & 15.8 & 4.1 \\
6 & 420 & 18.2 & 2.2 \\
7 & 78 & 18 & 0.72 \\
\hline
\end{tabular}

current density of $20 \mathrm{~mA} / \mathrm{cm}^{2}$. The voltages are obtained from Figure 3(a) at a constant current density of $20 \mathrm{~mA} / \mathrm{cm}^{2}$. Furthermore, the luminance and the luminous efficiency are got and corresponded from above various voltages via Figures 4(a) and 5, respectively. And then it is obvious that the efficiency of the device with buffer layer of $4 \mathrm{~nm}$ is better than that of the one without buffer layer. The brightness and efficiency of electroluminescent (EL) devices increased with the thickness of the $\mathrm{SiO}_{2}$ buffer layer, but those drop after the maximum brightness and efficiency of EL devices, which can be attributed to excessively blocking the hole by the thick buffer layer. However, a good EL device should possess not only the high brightness but also the high luminous efficiency.

Shown in Figure 5 is luminous efficiency versus applied voltage curves for seven different devices, derived from the data shown in Figure 4. There is an optimization thickness of
$\mathrm{SiO}_{2}(4 \mathrm{~nm})$ for the luminous efficiency of the devices. At a given constant voltage of $13 \mathrm{~V}$, obviously the device with the $4 \mathrm{~nm}$ thick buffer layer was the most efficient one. In contrast, the device without the $\mathrm{SiO}_{2}$ buffer only showed a luminous efficiency of $8.8 \mathrm{~cd} / \mathrm{A}$ at the voltage of $13 \mathrm{~V}$. An increase in the thickness of the $\mathrm{SiO}_{2}$ buffer beyond $4 \mathrm{~nm}$ resulted in a gradual decrease in brightness and efficiency. No EL emission could be findable when the thickness of the layer exceeded $8 \mathrm{~nm}$. Device performance was improved by the use of a buffer layer consisting of $\mathrm{SiO}_{2}$. Although the exact role of the $\mathrm{SiO}_{2}$ buffer layer in the hole-injecting transporting process is not completely clear, the enhancements in brightness and efficiency of the devices may tentatively be attributed to an improved balance of the hole and electron injections, which results in enhancements of carrier recombination efficiency. In addition, some groups believe that the deposition of an ultrathin oxide layer prior to the organic material deposition may smooth the interface and lead to a more homogeneous adhesion of the HBL to the anode [16-19].

The topography of $\mathrm{SiO}_{2}$ on ITO was acquired ex situ using atomic force microscopy (AFM). Figures 6(a)-6(d) show the topographical images that present the surface root mean square (RMS) roughness for ITO and surfaces obtained after depositing $\mathrm{SiO}_{2}$ of $2,3,4,5 \mathrm{~nm}$ on ITO. The RMS roughness is $1.581,1.358,1.128$, and $1.306 \mathrm{~nm}$, respectively. That reveals that ITO has a relatively smooth surface. In the 2 and $3 \mathrm{~nm}$ thickness, the surface morphologies are island structure and small quantity of spikes; a few nanometers in height on bare ITO surfaces indicate that the grains coalesce and fill in the channel between the grain and the poor surface uniformity. In addition, there is an optimization thickness of $\mathrm{SiO}_{2}(4 \mathrm{~nm})$ for the low RMS roughness of surface; the structure of island 
and spikes have fallen away little by little. In fact, the smooth uniformity of film surface for improving interface contact of the ultrathin $\mathrm{SiO}_{2}$ layer with organic layer is important for the injection and transmission properties of carrier. Therefore, carrier can be easy to inject through from ITO to organic mediums when the device is properly biased.

\section{Conclusions}

In summary, the devices with the insertion of an ultrathin $\mathrm{SiO}_{2}$ buffer layer between ITO and NPB showed enhanced hole-injection efficiency, higher EL efficiency, and operational stability that may be attributed to an improved current balance of the hole and electron injections, resulting mainly from the blocking of the injected holes by the buffer layer. In other words, this buffer layer improves FOLED efficiency without modifying the electrode work function or requiring additional organic layers. Various techniques, including physical and electrical characterizations, show that a smoother $\mathrm{SiO}_{2}(4 \mathrm{~nm}) / \mathrm{NPB}$ interface versus ultrathin $\mathrm{SiO}_{2}$ layers is a clear advantage for a FOLED. However, the buffer layer can be to control the emission performance of the FOLED, offering further promise for innovation optoelectronic application.

\section{Conflict of Interests}

The authors declare that there is no conflict of interests regarding the publication of this paper.

\section{Acknowledgment}

This work was partially supported by the National Science Council of Taiwan under Contract no. NSC102-2221-E-390019-MY2.

\section{References}

[1] C. Hosokawa, M. Eida, M. Matsuura, K. Fukuoka, H. Nakamura, and T. Kusumoto, "Organic multi-color electroluminescence display with fine pixels," Synthetic Metals, vol. 91, no. 1-3, pp. 3-7, 1997.

[2] Y. Kijima, N. Asai, N. Kishii, and S.-I. Tamura, "RGB luminescence from passive-matrix organic LED's," IEEE Transactions on Electron Devices, vol. 44, no. 8, pp. 1222-1228, 1997.

[3] J. Y. Lee, J. H. Kwon, and H. K. Chung, "High efficiency and low power consumption in active matrix organic light emitting diodes," Organic Electronics, vol. 4, no. 2-3, pp. 143-148, 2003.

[4] T. Dobbertin, E. Becker, T. Benstem et al., "OLED matrix displays: in-line process technology and fundamentals," Thin Solid Films, vol. 442, no. 1-2, pp. 132-139, 2003.

[5] P. E. Burrows, G. L. Graff, M. E. Gross et al., "Ultra barrier flexible substrates for flat panel displays," Displays, vol. 22, no. 2, pp. 65-69, 2001.

[6] Z. Xie, L.-S. Hung, and F. Zhu, "A flexible top-emitting organic light-emitting diode on steel foil," Chemical Physics Letters, vol. 381, no. 5-6, pp. 691-696, 2003.
[7] P. Melpignano, S. Sinesi, G. Rotaris et al., "Optical coupling of flexible microstructured organic light sources for automotive applications," Synthetic Metals, vol. 139, no. 3, pp. 913-916, 2003.

[8] F. Papadimitrakopoulos, X.-M. Zhang, and K. A. Higginson, "Chemical and morphological stability of aluminum tris(8hydroxyquinoline) (Alq3): effects in light-emitting devices," IEEE Journal on Selected Topics in Quantum Electronics, vol. 4, no. 1, pp. 49-57, 1998.

[9] Y. Qiu, Y. Gao, L. Wang, and D. Zhang, "Efficient light emitting diodes with teflon buffer layer," Synthetic Metals, vol. 130, no. 3, pp. 235-237, 2002.

[10] S. M. Tadayyon, H. M. Grandin, K. Griffiths, P. R. Norton, H. Aziz, and Z. D. Popovic, "CuPc buffer layer role in OLED performance: a study of the interfacial band energies," Organic Electronics, vol. 5, no. 4, pp. 157-166, 2004.

[11] L. Li, M. Guan, G. Cao, Y. Li, and Y. Zeng, "Low operatingvoltage and high power-efficiency OLED employing $\mathrm{MoO}_{3}$ doped CuPc as hole injection layer," Displays, vol. 33, no. 1, pp. 17-20, 2012.

[12] H.-H. Huang, S.-Y. Chu, P.-C. Kao, Y.-C. Chen, M.-R. Yang, and Z.-L. Tseng, "Enhancement of hole-injection and power efficiency of organic light emitting devices using an ultra-thin $\mathrm{ZnO}$ buffer layer," Journal of Alloys and Compounds, vol. 479, no. 1-2, pp. 520-524, 2009.

[13] B. J. Chen, X. W. Sun, Y. Divayana, and B. K. Tay, "Improving organic light-emitting devices by modifying indium tin oxide anode with an ultrathin tetrahedral amorphous carbon film," Journal of Applied Physics, vol. 98, no. 4, Article ID 046107, pp. $1-3,2005$.

[14] H. H. Kim, T. M. Miller, E. H. Westerwick et al., "Silicon compatible organic light emitting diode," Journal of Lightwave Technology, vol. 12, no. 12, pp. 2107-2113, 1994.

[15] J. M. Shannon, "Reducing the effective height of a schottky barrier using low-energy ion implantation," Applied Physics Letters, vol. 24, no. 8, pp. 369-371, 1974.

[16] G. Cao, L. Li, M. Guan, J. Zhao, Y. Li, and Y. Zeng, "Stable organic solar cells employing $\mathrm{MoO}_{3}$-doped copper phthalocyanine as buffer layer," Applied Surface Science, vol. 257, no. 22, pp. 9382-9385, 2011.

[17] L. Hou, P. Liu, Y. Li, and C. Wu, "Enhanced performance in organic light-emitting diodes by sputtering $\mathrm{TiO}_{2}$ ultra-thin film as the hole buffer layer," Thin Solid Films, vol. 517, no. 17, pp. 4926-4929, 2009.

[18] C. O. Poon, F. L. Wong, S. W. Tong, R. Q. Zhang, C. S. Lee, and S. T. Lee, "Improved performance and stability of organic lightemitting devices with silicon oxy-nitride buffer layer," Applied Physics Letters, vol. 83, no. 5, pp. 1038-1040, 2003.

[19] H. Youn and M. Yang, "Solution processed polymer lightemitting diodes utilizing a $\mathrm{ZnO} /$ organic ionic interlayer with al cathode," Applied Physics Letters, vol. 97, no. 24, Article ID 243302, 2010. 

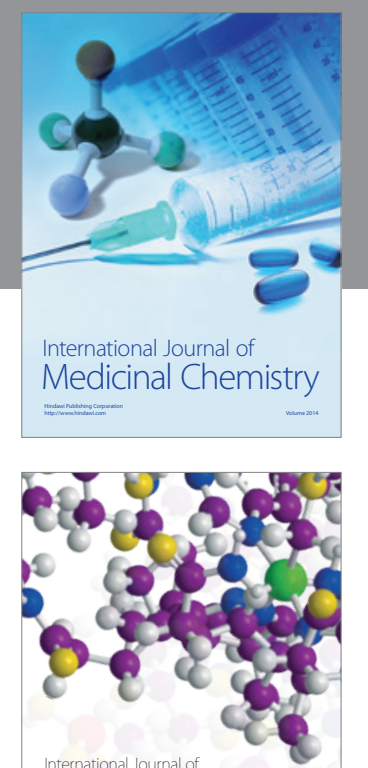

\section{Carbohydrate} Chemistry

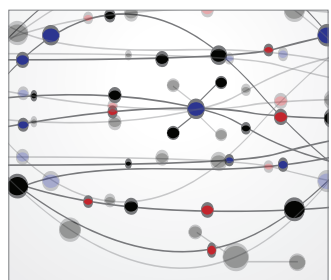

The Scientific World Journal
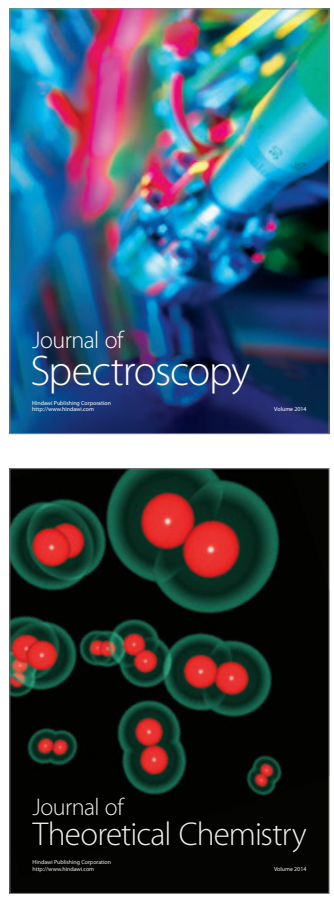
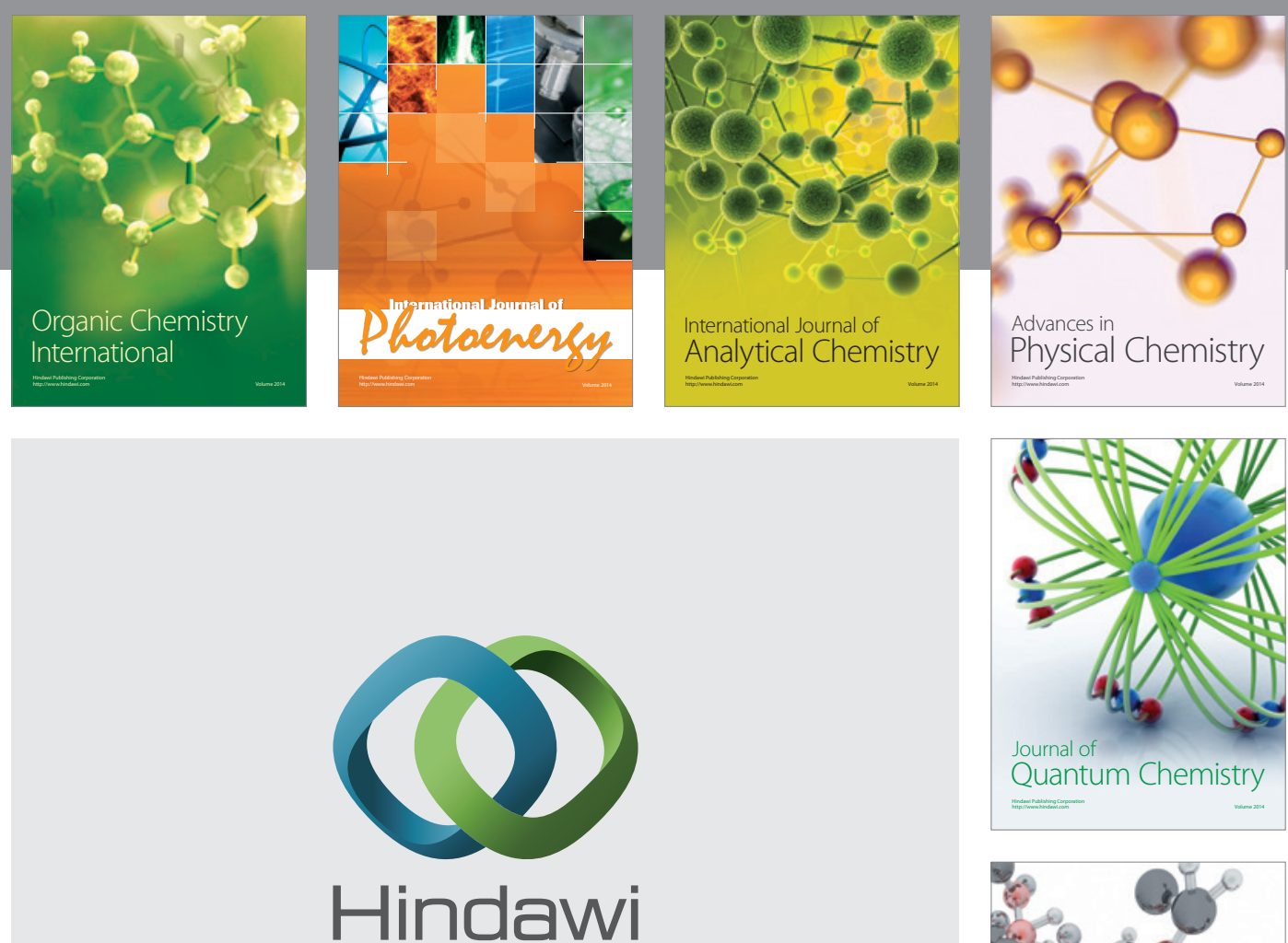

Submit your manuscripts at

http://www.hindawi.com

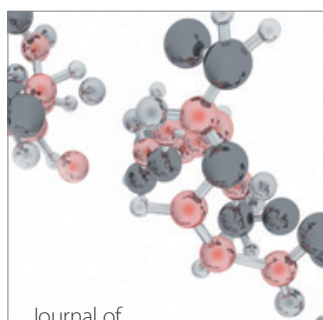

Analytical Methods

in Chemistry

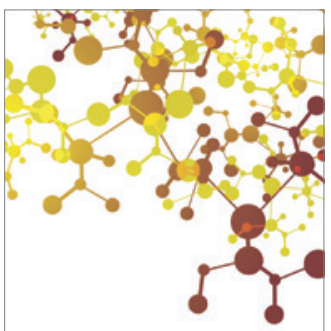

Journal of

Applied Chemistry

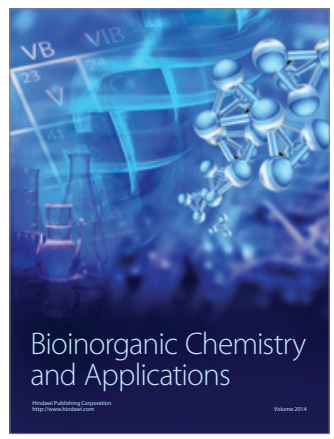

Inorganic Chemistry
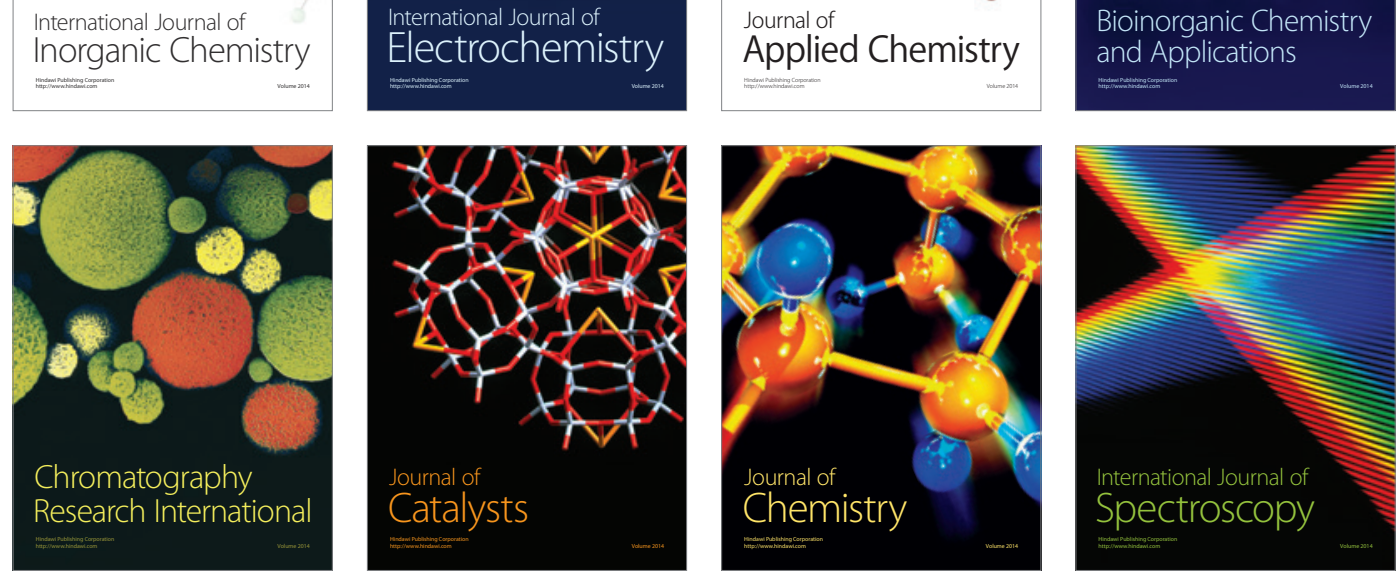